\title{
Diagnosis and management of non-alcoholic fatty liver disease
}

\author{
Erica Jennison, ${ }^{1}$ Janisha Patel, ${ }^{2}$ Eleonora Scorletti, ${ }^{3}$ Christopher D Byrne ${ }^{\oplus 4}$
}

${ }^{1}$ Chemical Pathology, University Hospital Southampton NHS Foundation Trust, Southampton, UK

${ }^{2}$ Hepatology, University Hospital Southampton NHS Foundation

Trust, Southampton, UK

${ }^{3}$ Human Development and Health, University of

Southampton, Southampton, UK

${ }^{4}$ The Institute of Developmental

Sciences, University of

Southampton, Southampton, UK

\section{Correspondence to}

Dr Erica Jennison, Chemical

Pathology, University Hospital

Southampton NHS Foundation

Trust, Southampton S016 6YD

UK; erica.jennison@uhs.nhs.uk

Received 22 February 2019

Revised 8 April 2019

Accepted 14 April 2019

Published Online First 13 May 2019

Check for updates

(C) Author(s) (or their employer(s)) 2019. No commercial re-use. See rights and permissions. Published by BMJ.

To cite: Jennison E, Patel J,

Scorletti E, et al.

Postgrad Med J

2019:95:314-322

\section{ABSTRACT}

Non-alcoholic fatty liver disease (NAFLD) is the most common chronic liver disease in Western industrialised countries. The prevalence of NAFLD is increasing in parallel with the global rise in obesity and type 2 diabetes mellitus. NAFLD represents a spectrum of liver disease severity. NAFLD begins with accumulation of triacylglycerols in the liver (steatosis), and is defined by hepatic fatty infiltration amounting to greater than $5 \%$ by liver weight or the presence of over $5 \%$ of hepatocytes loaded with large fat vacuoles. In almost a quarter of affected individuals, steatosis progresses with the development of liver inflammation to non-alcoholic steatohepatitis (NASH). NASH is a potentially progressive liver condition and with ongoing liver injury and cell death can result in fibrosis. Progressive liver fibrosis may lead to the development of cirrhosis in a small proportion of patients. With the growing prevalence of NAFLD, there is an increasing need for a robust, accurate and non-invasive approach to diagnosing the different stages of this condition. This review will focus on (1) the biochemical tests and imaging techniques used to diagnose the different stages of NAFLD; and (2) a selection of the current management approaches focusing on lifestyle interventions and pharmacological therapies for NAFLD.

\section{INTRODUCTION}

Non-alcoholic fatty liver disease (NAFLD) is the most common chronic liver disease in Western industrialised countries and affects around 25\% of the European adult population. ${ }^{1}$ The prevalence of NAFLD is increasing in parallel with the global rise in obesity and type 2 diabetes mellitus (T2DM). ${ }^{2}$ NAFLD is predicted to soon be the main indication for liver transplantation worldwide. ${ }^{3}$ The condition is defined by fatty infiltration of the liver amounting to greater than $5 \%$ by liver weight or the presence of over $5 \%$ of hepatocytes loaded with large fat vacuoles, in the absence of other causes of fatty liver disease such as alcohol. The disease is heterogeneous and develops through different stages to potential hepatocellular carcinoma, and/ or cirrhosis with end-stage liver disease that may necessitate liver transplantation to save the patient's life (figure 1).

The first stage in the development of NAFLD is isolated hepatic steatosis, defined as fat accumulation without significant inflammation or hepatocellular injury. In around $10 \%-25 \%$ of subjects, the disease progresses to non-alcoholic steatohepatitis (NASH), characterised by histological lobular inflammation and hepatocyte ballooning. In 20\% of patients with $\mathrm{NASH}$, the condition progresses resulting in liver fibrosis. ${ }^{4}$ Accumulation of fibrosis can lead to liver cirrhosis, and cirrhosis-related complications such as hepatocellular carcinoma. ${ }^{5}$ The presence of NAFLD and liver fibrosis is associated with significant morbidity and an increase in liver-related mortality. ${ }^{6}$ NAFLD is an independent risk factor for T2DM and cardiovascular disease, ${ }^{78}$ the latter being the most common cause of death in this group. ${ }^{910}$

\section{INVESTIGATIONS AND DIAGNOSIS OF NAFLD}

A validated approach to the diagnosis of NAFLD does not yet exist. Liver biopsy is heavily relied on in clinical trials for diagnosis of NAFLD and for testing the efficacy of the intervention. Hepatic biopsies are flawed, however, as a specimen only represents $\sim 1 / 50000$ of the liver volume, which can lead to false negatives due to the heterogeneity of liver disease in NAFLD. ${ }^{11}$ In clinical practice a less invasive and more pragmatic approach is necessary, especially given the growing prevalence of the disease and because of the need to monitor changes in the liver condition over time. Figure 2 illustrates a pragmatic algorithm for the diagnosis and management of NAFLD. The clinical importance of NAFLD and the limitations of liver biopsy have increased the need for accurate and non-invasive investigative techniques. Table 1 summarises the investigations used to diagnose the different stages of NAFLD.

\section{Clinical features and routine biochemical tests used to diagnose NAFLD}

The diagnosis of NAFLD requires evidence of hepatic steatosis in the absence of other causes of liver fat accumulation. NAFLD is often suspected in clinical practice when an individual with features of the metabolic syndrome (MetS) is found to have an increase in serum aminotransferase levels. Almost $80 \%$ of patients with NAFLD, however, have no biochemical abnormality, which has several possible explanations. ${ }^{12}$ Reference ranges for alanine transaminase (ALT) often overestimate the upper limit of normal (ULN), given they are calculated assuming the general population does not have undiagnosed liver disease such as NAFLD. A large study that excluded individuals at risk of liver dysfunction, including those with a body mass index (BMI) $\geq 25 \mathrm{~kg} / \mathrm{m}^{2}$, proposed a ULN for ALT of $30 \mathrm{IU} / \mathrm{L}$ for men and $19 \mathrm{IU} / \mathrm{L}$ for women. ${ }^{13}$ Additionally, aminotransferase levels typically fall as NAFLD progresses and fibrosis develops, and therefore in 


\section{Features of the Metabolic Syndrome:}

- Abdominal Obesity: Waist circumference: men: $\geq 102 \mathrm{~cm}$, women: $\geq 88 \mathrm{~cm}$

- Hypertriglyceridemia: $\geq 1.7 \mathrm{mmol} / \mathrm{L}$

- Low HDL: men: $<1.04 \mathrm{mmol} / \mathrm{dL}$, women: $<1.30 \mathrm{mmol} / \mathrm{dL}$

- Hypertension

- High fasting glucose: $>6.1 \mathrm{mmol} / \mathrm{L}$

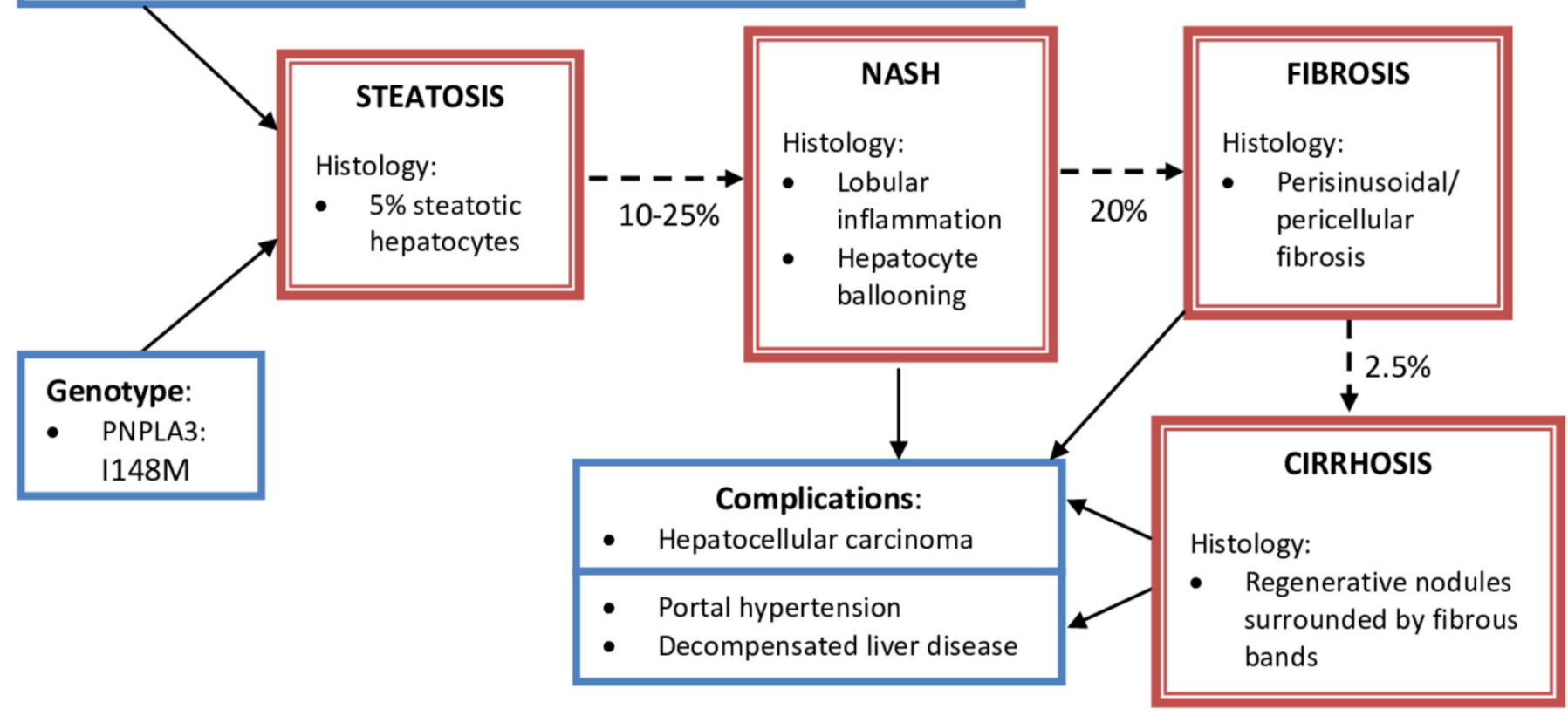

Figure 1 Common risk factors for NAFLD and characteristics and spectrum of liver disease in NAFLD. HDL, high-density lipoprotein; NAFLD, nonalcoholic fatty liver disease; NASH, non-alcoholic steatohepatitis; PNPLA3; patatin-like phospholipase domain-containing protein-3.

the later stages of the disease liver biochemistry may appear normal.

The components of the MetS (see figure 1) are closely associated with NAFLD. Nearly two-thirds of people with obesity and T2DM and half the patients with hyperlipidaemia and hypertension have fat identified on liver ultrasound. ${ }^{14-18}$ The presence of multiple features of the MetS is associated with more severe NAFLD-related liver disease and a higher likelihood of progression to NASH and liver fibrosis. ${ }^{19} 20$

Scoring systems which use the association between NAFLD and the MetS have been developed to identify those who require investigation for NAFLD. Two common examples are the Fatty Liver Index (includes BMI, waist circumference, gamma-glutamyltransferase and triglycerides) and the NAFLD Liver Fat Score (includes the presence of the MetS, T2DM, fasting serum insulin, aspartate aminotransferase and the aspartate aminotransferase/alanine aminotransferase ratio). Both algorithms are widely available and accurately correlate with more objective measures of fat seen on ultrasound. ${ }^{21} 22$

NAFLD can develop in those without features of MetS, which may reflect genetic factors involved in the pathogenesis of hepatic steatosis and inflammation. Recent focus has fallen on the patatin-like phospholipase domain-containing protein-3 (PNPLA3) gene, which codes for a membrane-associated protein expressed in hepatocytes and adipocytes. This protein has a role in hepatic hydrolysis of triglycerides and excretion of very low density lipoprotein (VLDL) ${ }^{23}$ A single-nucleotide polymorphism in PNPLA3 I148M (or rs738409) is present in around $20 \%$ of the population. ${ }^{24}$ This variant has a significant effect on enzymatic activity causing a disruption of triglyceride hydrolysis and subsequently leading to defective VLDL secretion. ${ }^{25} 26$ As a consequence there is an increase in hepatic steatosis and hepatic inflammation, as seen in homozygous individuals who exhibit twice the level of hepatic fat content compared with non-carriers of this variant. ${ }^{27}$

When the diagnosis of NAFLD is suspected, it is important that alternative causes for hepatic fat accumulation or liver dysfunction are ruled out. This involves a full history and examination to assess alcohol intake, medications, family history and risk of exposure to viral hepatitis. Following this a biochemical liver screen should be performed involving hepatitis B and C serology, liver autoantibodies, immunoglobulins, alpha 1 antitrypsin, ferritin and caeruloplasmin concentrations in patients $<50$ years.

\section{Imaging assessment of hepatic steatosis}

The diagnosis of NAFLD requires evidence of hepatic steatosis. Various imaging modalities are available, but ultrasound is a pragmatic and widely accepted first-line investigation. Ultrasound has the significant advantage of being non-invasive, radiation-free, easily available and low cost. Additionally this technique can be used to assess the liver structure and identify liver lesions and other pathologies such as gallstones or liver metastases. Ultrasound has good sensitivity $(85 \%)$ and specificity (95\%) compared with histology in identifying moderate and severe steatosis. ${ }^{28}{ }^{29}$ The main disadvantage is the low sensitivity when less than $20 \%-30 \%$ of hepatocytes are steatotic. ${ }^{30}$ Additionally, an accurate quantitative assessment is not performed and an element of operator dependency 


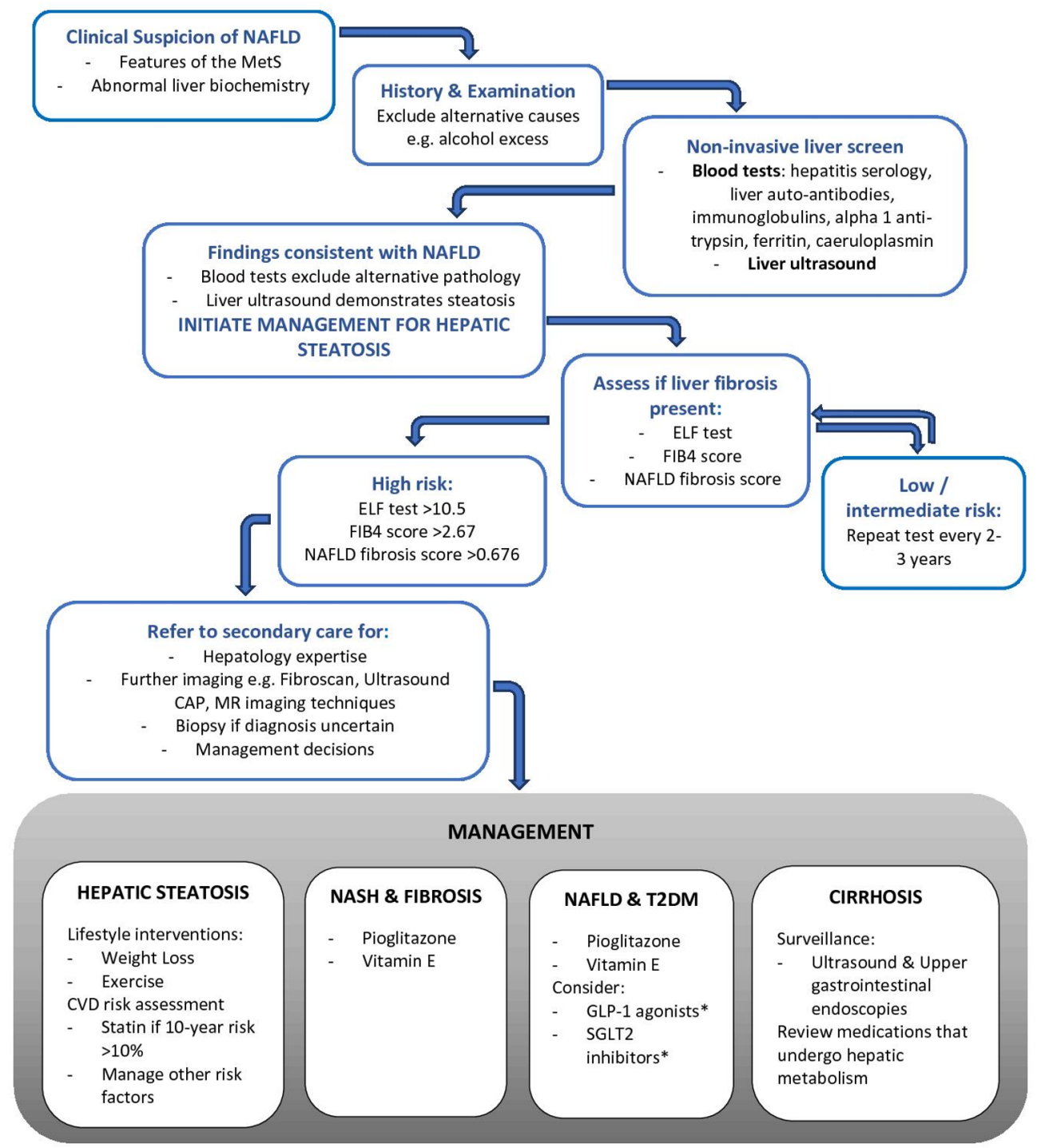

Figure 2 An algorithm for the diagnosis and management of NAFLD. *GLP-1 agonists and SGLT2 inhibitors may be considered to treat hyperglycaemia in patients with T2DM and NAFLD, but further evidence is needed before such drugs can be advised specifically to treat NAFLD. CAP, Controlled Attenuation Parameter; CVD, cardiovascular disease; ELF, Enhanced Liver Fibrosis; FIB4, Fibrosis-4; GLP-1, glucagon-like-peptide-1; MetS, metabolic syndrome; MR, magnetic resonance; NAFLD, non-alcoholic fatty liver disease; NASH, non-alcoholic steatohepatitis; SGLT2, sodium-glucose cotransporter-2; T2DM, type 2 diabetes mellitus.

is involved. ${ }^{31}$ As hepatic fibrosis may increase hepatic echogenicity, the presence of underlying chronic liver disease can reduce the accuracy in assessing liver fat. ${ }^{32}$ To overcome the limitations of ultrasound in evaluating low levels of hepatic steatosis, more advanced ultrasound techniques have been developed. Controlled Attenuation Parameter (CAP) uses ultrasound with vibration-controlled elastography to measure the degree of ultrasound attenuation due to hepatic fat. CAP can detect milder degrees of steatosis compared with conventional ultrasound and correlates well with liver biopsies. ${ }^{33}$ Computer-assisted quantitative techniques such as combined ultrasound hepatic/renal echo-intensity ratio and ultrasound hepatic echo-intensity attenuation rate evaluation can detect $<15 \%$ hepatic steatosis with a sensitivity and specificity of $81.4 \%$ and $100 \%$, respectively. ${ }^{34}$

Like ultrasound, CT is widely available, easy to perform and accurate at detecting moderate and severe hepatic steatosis. ${ }^{35}$ Unfortunately, this technique is also unreliable at detecting low levels of hepatic steatosis. Additionally, the potential hazard of ionising radiation makes CT unsuitable for longitudinal monitoring of patients with NAFLD.

MRI techniques are highly accurate at detecting hepatic steatosis. The detection of hepatic steatosis is limited in conventional magnetic resonance (MR) by T1 bias, T2* decay and signal interference caused by protons in fat. ${ }^{36}$ Several methods have therefore been developed with superior accuracy over conventional MRI. MR spectroscopy (MRS) measures the hepatic proton density fat fraction (PDFF), which is an objective biomarker of liver fat content. MRS is not yet widely available, is time-consuming and typically samples only a portion of the liver. MRI-PDFF, however, can be used with any clinical MR platform, is more time-efficient and estimates hepatic PDFF across the entire liver. ${ }^{37}$ Shortcomings of MRI-PDFF include underestimation of hepatic steatosis in patients with moderate to severe fatty infiltration or fibrosis. ${ }^{38}$

\section{Identifying progression of steatosis to NASH}

Currently there is no readily available, reliable and non-invasive method to identify the progression of steatosis to NASH. 
Table 1 Invasive and non-invasive techniques for diagnosing the different stages of NAFLD

\begin{tabular}{|c|c|c|c|c|}
\hline NAFLD stage & Investigation & Findings consistent with NAFLD stage & Advantages & Disadvantages \\
\hline \multirow[t]{6}{*}{$\begin{array}{l}\text { Hepatic } \\
\text { steatosis }\end{array}$} & Biopsy & Steatosis in $>5 \%$ of hepatocytes. & $\begin{array}{l}\text { Gold standard for diagnosis of hepatic } \\
\text { steatosis. } \\
\text { - Used for diagnostic uncertainty. }\end{array}$ & $\begin{array}{l}\text { False negatives. } \\
\text { Expensive. } \\
\text { Invasive. }\end{array}$ \\
\hline & Fatty Liver Index & - $\geq 60$ predicts hepatic steatosis. & $\begin{array}{l}\text { Non-invasive. } \\
\text { Inexpensive. } \\
\text { Widely available. } \\
\text { Validated against ultrasound. }\end{array}$ & - Not validated against liver histology. \\
\hline & NAFLD Liver Fat Score & $\begin{array}{l}>0.640 \text { predicts hepatic steatosis (sensitivity } \\
84 \% \text {, specificity } 69 \% \text { ). }{ }^{22}\end{array}$ & $\begin{array}{l}\text { Non-invasive. } \\
\text { Inexpensive. } \\
\text { Validated against ultrasound. }\end{array}$ & $\begin{array}{l}\text { Requires serum insulin. } \\
\text { Not validated against histology. }\end{array}$ \\
\hline & Ultrasound & $\begin{array}{l}\text { Liver echogenicity > renal cortex and spleen } \\
\text { echogenicity. } \\
\text { Loss of definition of the diaphragm. } \\
\text { Poor delineation of the intrahepatic } \\
\text { architecture. }\end{array}$ & $\begin{array}{l}\text { Accurate if }>30 \% \text { hepatic steatosis. } \\
\text { Non-invasive. } \\
\text { Inexpensive. } \\
\text { Widely available. } \\
\text { Can rule out other pathologies. }\end{array}$ & $\begin{array}{l}\text { Poor sensitivity if }<30 \% \text { hepatic } \\
\text { steatosis (improved by CAP and } \\
\text { computer software technology). }\end{array}$ \\
\hline & CT & $\begin{array}{l}\text { Liver attenuation }<\text { spleen attenuation (by }>10 \\
\text { Hounsfield units). } \\
\text { - Liver attenuation }<40 \text { Hounsfield units. }^{77}\end{array}$ & $\begin{array}{l}\text { Accurate if }>30 \% \text { hepatic steatosis. } \\
\text { Can rule out other pathologies. } \\
\text { Widely available. }\end{array}$ & $\begin{array}{l}\text { Poor sensitivity if }<30 \% \text { hepatic } \\
\text { steatosis. } \\
\text { Radiation exposure. }\end{array}$ \\
\hline & $\begin{array}{l}\text { MR imaging (MRS, } \\
\text { MRI-PDFF) }\end{array}$ & $\begin{array}{l}\text { Estimation of liver fat \%: fraction of MR-visible } \\
\text { protons bound to fat in relation to all MR- } \\
\text { visible protons in the liver. }\end{array}$ & $\begin{array}{l}\text { High accuracy at detecting even low levels } \\
\text { of hepatic steatosis. }\end{array}$ & $\begin{array}{l}\text { Time-consuming. } \\
\text { Expensive. } \\
\text { MRS: samples one portion of the liver. } \\
\text { MRI-PDFF: reduced accuracy if fibrosis } \\
\text { or moderate/severe hepatic steatosis } \\
\text { present. }\end{array}$ \\
\hline \multirow[t]{2}{*}{ NASH } & Biopsy & $\begin{array}{l}\text { Lobular inflammation. } \\
\text { Hepatocyte ballooning. }\end{array}$ & $\begin{array}{l}\text { Gold standard for diagnosis of NASH. } \\
\text { Used for diagnostic uncertainty. } \\
\text { Used before and during pharmacological } \\
\text { intervention. }\end{array}$ & $\begin{array}{l}\text { False negatives. } \\
\text { Expensive. } \\
\text { Invasive. }\end{array}$ \\
\hline & Multiparametric MR & $\begin{array}{l}\text { LIF score }>1.4 \text { (sensitivity } 91 \% \text {, specificity } \\
52 \%)^{41}\end{array}$ & $\begin{array}{l}\text { High diagnostic accuracy. } \\
\text { Non-invasive. } \\
\text { Uses conventional MR technology. }\end{array}$ & $\begin{array}{l}\text { Not yet widely available. } \\
\text { LIF score requires further validation. }\end{array}$ \\
\hline \multirow[t]{7}{*}{$\begin{array}{l}\text { Fibrosis and } \\
\text { cirrhosis }\end{array}$} & Biopsy & $\begin{array}{l}\text { F0: no fibrosis. } \\
\text { F1: perisinusoidal/pericellular fibrosis OR } \\
\text { portal/periportal fibrosis. } \\
\text { F2: perisinusoidal/pericellular fibrosis AND } \\
\text { portal/periportal fibrosis. } \\
\text { F3: bridging fibrosis. } \\
\text { F4: cirrhosis. }\end{array}$ & $\begin{array}{l}\text { Gold standard for diagnosis of liver fibrosis } \\
\text { and cirrhosis. }\end{array}$ & $\begin{array}{l}\text { Expensive. } \\
\text { Invasive. } \\
\text { Not suitable for long-term monitoring. }\end{array}$ \\
\hline & NAFLD Fibrosis Score & $\begin{array}{l}\text { Advanced fibrosis: }>0.676 .^{79} \\
\text { Different thresholds based on age to exclude }^{\text {advanced fibrosis. }}{ }^{79}\end{array}$ & $\begin{array}{l}\text { Widely available. } \\
\text { Above threshold: accurate at predicting } \\
\text { advanced fibrosis. } \\
\text { Below threshold: accurate at ruling out } \\
\text { advanced fibrosis. }\end{array}$ & $\begin{array}{l}\text { Intermediate score range: poor } \\
\text { diagnostic performance. } \\
\text { Inaccurate in those }<35 \text { years of age. }{ }^{80}\end{array}$ \\
\hline & FIB-4 Score & $\begin{array}{l}\text { Advanced fibrosis: }>2.67 .^{44} \\
\text { Different thresholds based on age to exclude } \\
\text { advanced fibrosis. }\end{array}$ & $\begin{array}{l}\text { Widely available. } \\
\text { Above threshold: accurate at predicting } \\
\text { advanced fibrosis. } \\
\text { Below threshold: accurate at ruling out } \\
\text { advanced fibrosis. }\end{array}$ & $\begin{array}{l}\text { Intermediate score range: poor } \\
\text { diagnostic performance. } \\
\text { Inaccurate in those }<35 \text { years of age. }{ }^{80}\end{array}$ \\
\hline & ELF test & Advanced fibrosis: $\geq 10.51 .45$ & $\begin{array}{l}\text { Widely available. } \\
\text { Above threshold: accurate at predicting } \\
\text { advanced fibrosis. } \\
\text { Below threshold: accurate at ruling out } \\
\text { advanced fibrosis. }\end{array}$ & $\begin{array}{l}\text { Intermediate score range: poor } \\
\text { diagnostic performance. }\end{array}$ \\
\hline & TE (FibroScan) & $\begin{array}{l}\text { Advanced fibrosis: }>7.6 \mathrm{kPA}^{81} \\
\text { Cirrhosis }>13 \mathrm{kPA}^{82}\end{array}$ & $\begin{array}{l}\text { Above threshold: accurate at predicting } \\
\text { advanced fibrosis. } \\
\text { Below threshold: accurate at ruling out } \\
\text { advanced fibrosis. }\end{array}$ & $\begin{array}{l}\text { Obesity can cause inaccuracy. } \\
\text { Intermediate score range: poor } \\
\text { diagnostic performance. }\end{array}$ \\
\hline & $\begin{array}{l}\text { Acoustic radiation } \\
\text { force impulse }\end{array}$ & $\begin{array}{l}\text { Advanced fibrosis: } 1.63 \mathrm{~m} / \mathrm{s}^{83} \\
\text { Cirrhosis: } 1.94 \mathrm{~m} / \mathrm{s}^{83}\end{array}$ & $\begin{array}{l}\text { Above threshold: accurate at predicting } \\
\text { advanced fibrosis. } \\
\text { Non-invasive. }\end{array}$ & $\begin{array}{l}\text { Steatosis and inflammation can cause } \\
\text { inaccuracy. }\end{array}$ \\
\hline & Multiparametric MR & Cirrhosis: LIF score $>3.0 .^{41}$ & $\begin{array}{l}\text { High diagnostic accuracy. } \\
\text { Non-invasive. } \\
\text { Uses conventional MR technology. }\end{array}$ & $\begin{array}{l}\text { Not yet widely available. } \\
\text { LIF score requires further validation. }\end{array}$ \\
\hline
\end{tabular}

CAP, Controlled Attenuation Parameter; ELF, Enhanced Liver Fibrosis; FIB-4, Fibrosis-4; LIF, liver inflammation and fibrosis; MR, magnetic resonance; MRI-PDFF, MRI-proton density fat fraction; MRS, MR spectroscopy; NAFLD, non-alcoholic fatty liver disease; NASH, non-alcoholic steatohepatitis; TE, transient elastography.

Identifying NASH has assumed considerable importance in clinical practice, because NASH is thought to be a progressive condition and efficacy of new drugs to induce resolution of NASH is a key end-point in clinical trials. It should be noted, however, that the presence of NASH per se does not predict liver outcomes, which likely represents the fact that NASH is a fluctuating disease which may not be assessed accurately on histological examination of a liver biopsy. Rather, it is the presence of liver fibrosis and specifically advanced fibrosis that predicts liver outcomes such as liver-related morbidity 
and mortality. The risk of NASH increases with the number of metabolic risk factors, which can be used to identify highrisk individuals. The search for an accurate biochemical biomarker of NASH is still ongoing. Current areas of interest include hepatic markers of apoptosis and cell turnover. ${ }^{39} 40$ Unfortunately, the most accurate diagnostic test for detecting NASH is still liver biopsy and that creates a clinical problem in managing patients with NAFLD. Undertaking serial liver biopsies over time is very expensive and is completely unacceptable to most clinicians as well as to patients.

Multiparametric MRI uses conventional MR technology but combines two or more quantitative techniques such as T1, T2* and PDFF to allow more accurate assessment of hepatic inflammation and fibrosis. LiverMultiScan is a multiparametric MR technique which uses an algorithm to calculate a liver inflammation and fibrosis (LIF) score. The LIF score has shown high diagnostic accuracy when compared with histology in detecting inflammation and fibrosis. ${ }^{41}$ Unlike acoustic-based techniques, multiparametric MR is unaffected by central adiposity and also has the potential to demonstrate which parts of the liver are affected. ${ }^{41}$ The LIF score has not yet been validated in large cohorts and a cost-benefit analysis has not been performed.

\section{Identifying progression of NASH to liver fibrosis and cirrhosis}

Diagnosing and staging liver fibrosis are essential in all patients with NAFLD to detect those patients with advanced fibrosis and cirrhosis who should be managed under a gastroenterology or hepatology service and screened for liver-related complications. Screening involves 6 monthly ultrasounds (with or without measurement of serum alpha-fetoprotein) as surveillance for hepatocellular carcinoma, and regular upper gastrointestinal endoscopies to identify and treat oesophageal varices. ${ }^{42}$

Simple biochemical markers of fibrosis such as low albumin, prolonged prothrombin time and thrombocytopaenia are non-invasive and inexpensive, but have poor reliability and are markers of advanced cirrhosis. Scoring system such as the NAFLD Fibrosis Score and the Fibrosis-4 (FIB-4) Score incorporate clinical features with simple biochemical results to identify those with liver fibrosis. ${ }^{43} 44$ The Enhanced Liver Fibrosis (ELF) algorithm is a more specialist biochemical test and has superior accuracy over other scoring systems. The algorithm combines three non-liver-specific serum markers of extracellular matrix remodelling and fibrogenesis: hyaluronic acid, the $\mathrm{N}$-terminal pro-peptide of collagen type III and tissue inhibitor of metalloproteinase-1. These scoring systems are accurate (above a certain threshold) at predicting advanced fibrosis and accurate (below a certain threshold) at excluding advanced fibrosis. ${ }^{45} 46$ The algorithms can therefore be used to identify patients with non-advanced liver fibrosis who can be managed in primary care. The intermediate ranges of these scoring systems have poor diagnostic performances and therefore create difficult management dilemmas. Generally, in these circumstances, the advice is that the algorithm is repeated every 2-3 years.

Transient elastography (TE) techniques, such as FibroScan, rely on the reduced elasticity brought on by deposition of fibrotic tissue in hepatic parenchyma as fibrosis progresses. TE gives a liver stiffness measurement using pulsed-echo ultrasound as a surrogate marker of fibrosis. The technique has been validated for several aetiologies of chronic liver disease including NAFLD. TE can accurately detect advanced disease with a sensitivity of $87 \%$ and specificity of $91 \%$ in detecting cirrhosis. ${ }^{47}$ TE has an accurate negative predictive value and can therefore be useful to reliably exclude advanced fibrosis; however, the optimum cut-off is yet to be determined. Inaccuracies can be caused by central obesity, cholestasis, liver congestion and operator inexperience. One study found that the failure rate (defined as no valid shots during TE) ranged from $1 \%$ in patients with a BMI $<25 \mathrm{~kg} / \mathrm{m}^{2}$ to $41.7 \%$ in patients with a BMI $>40 \mathrm{~kg} / \mathrm{m}^{2} .^{48}$ Similarly, the rate of unreliable results ranged from $12 \%$ in patients with a BMI $<25 \mathrm{~kg} /$ $\mathrm{m}^{2}$ to $53.6 \%$ in patients with a BMI $>40 \mathrm{~kg} / \mathrm{m}^{2} .{ }^{49}$

Acoustic radiation force impulse (ARFI) is another ultrasound-based imaging technique which relies on wave propagation speed to assess tissue stiffness and therefore the degree of liver fibrosis. The technique uses a standard ultrasound probe and relies on no external compression, therefore reducing operator dependency. ARFI is accurate in assessing moderate to severe fibrosis in patients with chronic liver disease. Unfortunately, in patients with NAFLD, the associated steatosis and inflammation can cause interference and inaccuracies. ${ }^{450}$

MR elastography (MRE), particularly three-dimensional MRE, has shown superiority over ultrasound-based techniques in the evaluation of fibrosis in NAFLD. ${ }^{51}$ The technique is restricted to specialist centres, which makes it largely unsuitable for widespread use. As discussed previously, multiparametric MR and the calculated LIF score can also be used to quantify hepatic fibrosis. Although initial results are promising, further validation of the LIF score in larger cohorts is required. ${ }^{52}$

\section{Role of liver biopsies in the diagnosis and monitoring of NAFLD}

Liver biopsy is the gold standard for diagnosing hepatic steatosis, NASH and liver fibrosis. Despite the associated risks and expense, biopsy still has a role in the diagnosis of NAFLD. Liver biopsy should be considered in all patients in whom the diagnosis remains uncertain. Additionally, in those with a high probability of liver fibrosis, a biopsy can be used to confirm the diagnosis. Liver biopsies are still used when treatment is being considered and to monitor the histological response to pharmacological therapies, not least because all the drugs that have shown to be effective in causing NASH resolution are only effective in a proportion of treated patients.

\section{TREATMENT OF NAFLD: LIFESTYLE AND DRUGS Lifestyle interventions for the management of NAFLD}

Current management of NAFLD is largely focused on lifestyle interventions to try and achieve weight loss (where appropriate) and to ameliorate underlying metabolic and cardiovascular risk factors. Even relatively small amounts of weight loss can result in significant reductions in liver fat percentage, improved insulin sensitivity, improvements in cardiometabolic risk factors and better long-term outcomes. A small randomised control trial showed that $7 \%$ weight loss led to histological improvements, including reduced steatosis, fewer ballooned hepatocytes and less lobular inflammation..$^{53}$ In general, calorie restriction, as opposed to alteration of macronutrient composition, seems to be the most important dietary intervention and has the biggest impact on reducing weight and improving the liver condition. ${ }^{54}$ Increased physical activity has also been shown to reduce hepatic steatosis, visceral adipose tissue and plasma free fatty acids, therefore decreasing the likelihood of developing NASH and liver fibrosis. ${ }^{55}$ Various mechanisms, involving adipocyte proinflammatory cytokines (eg, interleukin- 6 and tumour 
necrosis factor- $\alpha$ ), contribute to the important relationship between adipose tissue and the development and progression of NAFLD. ${ }^{56}$

Although weight loss is considered the most important intervention in NAFLD management, a weight-neutral Mediterranean diet has also been shown to produce benefit in reducing liver steatosis and improving insulin sensitivity. ${ }^{57}$ It has been speculated that via the increased intake of monounsaturated and polyunsaturated fatty acids and the decreased intake of saturated fatty acids, the Mediterranean diet may decrease hepatic lipogenesis and reduce hepatic steatosis. ${ }^{57}$

The disadvantage of lifestyle interventions is the difficulty associated with implementing and maintaining a calorie-restricted diet and increased physical activity. In order to achieve good compliance, lifestyle goals should be realistic for each patient. Given the association between NAFLD, MetS and cardiovascular disease, it is important that cardiovascular risk is assessed and comorbidities such as T2DM, dyslipidaemia and hypertension are treated in order to decrease cardiovascular risk in patients with NAFLD.

\section{Pharmacological treatment of NAFLD}

Many pharmacological interventions to limit the development and progression of NAFLD have been tested, although none are to date specifically licensed for the treatment of NAFLD. Table 2 summarises the medications currently recommended and a selection of drugs which may play a future role.

Pioglitazone is a licensed drug for the treatment of T2DM. Pioglitazone targets both adipose tissue metabolism and inflammation, acting through the transcription factor peroxisome proliferator-activated receptor gamma (PPAR $\gamma$ ). Pioglitazone reduces hepatic steatosis through increased uptake of fatty acids by adipocytes, and therefore reduces the flux of fatty acids to other organs, such as the liver. ${ }^{55}$ Pioglitazone also upregulates adiponectin, an adipokine with antisteatogenic

Table 2 Selected pharmacological treatments with evidence of efficacy in the treatment of NASH

\begin{tabular}{|c|c|c|c|c|}
\hline & Mechanism of action & Benefit & Indications & Limitations and side effects \\
\hline Pioglitazone & $\begin{array}{l}\text { Stimulates PPAR } \gamma \text { : } \\
\text { Reduces hepatic fatty } \\
\text { acid uptake due to an } \\
\text { increased uptake by } \\
\text { adipocytes. } \\
\text { Upregulates adiponectin. }\end{array}$ & $\begin{array}{l}>\text { Hepatic steatosis. } \\
\quad \downarrow \text { Inflammation. } \\
\quad \downarrow \text { Hepatocyte ballooning. } \\
>\quad \text { Improved glycaemic control. }\end{array}$ & $\begin{array}{l}\text { Treatment of biopsy- } \\
\text { proven NASH in patients } \\
\text { with or without T2DM. }\end{array}$ & $\begin{array}{l}\text { Weight gain. } \\
\text { Reported increase of congestive cardiac } \\
\text { failure, bladder cancer and osteoporosis. } \\
\text { Unclear if improves fibrosis. }\end{array}$ \\
\hline Vitamin $\mathrm{E}$ & $\begin{array}{l}\text { Antioxidative. } \\
\text { Anti-inflammatory. }\end{array}$ & $\begin{array}{l}>\quad \downarrow \text { Hepatic steatosis. } \\
>\quad \downarrow \text { Inflammation. } \\
>\quad \downarrow \text { Hepatocyte ballooning. } \\
>\quad \downarrow \text { Aminotransferase levels. }\end{array}$ & $\begin{array}{l}\text { Treatment of biopsy- } \\
\text { proven NASH in patients } \\
\text { with or without T2DM. }\end{array}$ & $\begin{array}{l}\text { Reported increase in risk of all-cause } \\
\text { mortality, haemorrhagic stroke and } \\
\text { prostate cancer. } \\
\text { Has not been investigated in individuals } \\
\text { with diabetes. }\end{array}$ \\
\hline Obeticholic acid & $\begin{array}{l}\text { FXR agonist: } \\
\text { Improves hepatic insulin } \\
\text { sensitivity. } \\
\text { Decreases } \\
\text { gluconeogenesis. }\end{array}$ & $\begin{array}{l}>\quad \downarrow \text { Inflammation. } \\
>\quad \downarrow \text { Hepatic lipogenesis. } \\
>\text { Improved fibrosis. }\end{array}$ & $\begin{array}{l}\text { Not currently } \\
\text { recommended to } \\
\text { specifically treat NAFLD. }\end{array}$ & $\begin{aligned} & \text { Raises LDL-C. } \\
& \text { Pruritus. } \\
& \text { Results from phase III trial awaited } \\
& \\
& \text { (REGENERATE). }\end{aligned}$ \\
\hline Elafibranor & $\begin{array}{l}\text { Stimulates PPAR } \alpha \text { and } \\
\text { PPAR } \delta \text { : } \\
\text { Improves insulin } \\
\text { sensitivity. } \\
\text { Anti-inflammation. }\end{array}$ & $\begin{array}{l}\downarrow \\
\downarrow \text { Imflammation. } \\
\text { factors. }\end{array}$ & $\begin{array}{l}\text { Not currently } \\
\text { recommended to } \\
\text { specifically treat NAFLD. }\end{array}$ & $\begin{array}{l}\text { No benefit shown in mild NASH. } \\
\text { Results from phase III trial awaited } \\
\text { (RESOLVE-IT). }\end{array}$ \\
\hline Selonsertib & $\begin{array}{l}\text { ASK1 inhibitor: } \\
\text { Inhibits hepatocyte } \\
\text { apoptosis. } \\
\text { Antifibrotic. }\end{array}$ & $\begin{array}{l}\downarrow \text { Hepatic steatosis. } \\
\text { Improved fibrosis. }\end{array}$ & $\begin{array}{l}\text { Not currently } \\
\text { recommended to } \\
\text { specifically treat NAFLD. }\end{array}$ & $\begin{array}{l}\text { Results from phase III trial awaited } \\
\text { (STELLAR 4). }\end{array}$ \\
\hline Cenicriviroc & $\begin{array}{l}\text { CCR2/5 antagonist: } \\
\text { Antifibrotic. } \\
\text { Anti-inflammatory. } \\
\text { Improves insulin } \\
\text { sensitivity. }\end{array}$ & $\begin{array}{l}\text { Improves glycaemic control. } \\
\text { Improves fibrosis. }\end{array}$ & $\begin{array}{l}\text { Not currently } \\
\text { recommended to } \\
\text { specifically treat NAFLD. }\end{array}$ & $\begin{array}{l}\text { Asymptomatic rise in amylase. } \\
\text { Results from phase III trial awaited } \\
\text { (AURORA). }\end{array}$ \\
\hline $\begin{array}{l}\text { GLP-1 agonist, for example, } \\
\text { liraglutide }\end{array}$ & $\begin{array}{l}\text { Inhibits glucagon } \\
\text { secretion. } \\
\text { Decreases hepatic } \\
\text { glucose production. } \\
\text { Delays gastric emptying. } \\
\text { Promotes satiety. }\end{array}$ & $\begin{array}{l}\quad \downarrow \text { inflammation. } \\
\quad \downarrow \text { Steatosis. } \\
\quad \downarrow \text { Fibrosis. } \\
\text { Weight loss. } \\
- \text { Improved glycaemic control. }\end{array}$ & $\begin{array}{l}\text { Not currently } \\
\text { recommended to } \\
\text { specifically treat NAFLD. }\end{array}$ & $\begin{array}{l}\text { Gastrointestinal upset. } \\
\text { Results from further trials awaited. }\end{array}$ \\
\hline SGLT2 inhibitors & $\begin{array}{l}\text { Inhibit SGLT2 in the proximal } \\
\text { convoluted tubule: } \\
\text { Glucosuria. } \\
\text { Altered lipid metabolism. }\end{array}$ & $\begin{array}{l}-\quad \downarrow \text { Aminotransferase levels. } \\
- \text { Weight loss. } \\
-\quad \downarrow \text { Fatty Liver Index. } \\
- \text { Improved glycaemic control. }\end{array}$ & $\begin{array}{l}\text { Not currently } \\
\text { recommended to } \\
\text { specifically treat NAFLD. }\end{array}$ & $\begin{array}{l}\text { Benefits only verified in small pilot } \\
\text { studies. } \\
\text { Results from further trials awaited. }\end{array}$ \\
\hline
\end{tabular}

ASK1, apoptosis signal-regulating kinase 1; AURORA, A Phase 3 Study to Evaluate the Efficacy and Safety of Cenicriviroc for the Treatment of Liver Fibrosis in Adult Subjects With Nonalcoholic Steatohepatitis; CCR2/5, C-C motif chemokine receptor-2/5; FXR, farnesoid X nuclear receptor; GLP-1, glucagon-like-peptide-1; LDL-C, low-density lipoprotein cholesterol; NAFLD, non-alcoholic fatty liver disease; NASH, non-alcoholic steatohepatitis; PPAR, peroxisome proliferator-activated receptor; REGENERATE, Randomized Global Phase 3 Study to Evaluate the Impact on NASH With Fibrosis of Obeticholic Acid Treatment; RESOLVE-IT, A Multicenter, Randomized, Double-Blind, Placebo-Controlled Phase III Study to Evaluate the Efficacy and Safety of Elafibranor in Patients With Nonalcoholic Steatohepatitis (NASH) and Fibrosis; SGLT2, sodium-glucose cotransporter-2; STELLAR 4, Safety and Efficacy of Selonsertib in Adults With Compensated Cirrhosis Due to Nonalcoholic Steatohepatitis; T2DM, type 2 diabetes mellitus. 
and insulin-sensitising properties. ${ }^{58}$ In a significant proportion of individuals with NASH, these effects lead to a reduction in hepatic steatosis, inflammation and histopathological ballooning. ${ }^{59} 60$ Current evidence suggests the maximal metabolic improvements are achieved within 1 year of therapy. ${ }^{61}$ Unfortunately the role of pioglitazone in NAFLD is limited by its side effect profile, particularly weight gain. Additionally, the evidence that this class of medication benefits fibrosis is conflicting. ${ }^{5960}$ This is important considering that fibrosis is the only histological determinant that can predict both all-cause mortality and liver-related mortality. ${ }^{62}$

The pathogenesis of NAFLD is thought to involve oxidative stress, which contributes to inflammation and hepatocyte damage. Given the antioxidative and anti-inflammatory effects of vitamin $\mathrm{E}$, its role as a therapeutic agent has been explored. ${ }^{63}$ Trials have shown an improvement in steatosis, inflammation and hepatocyte ballooning, often accompanied by a fall in aminotransferase levels. ${ }^{53}$ Concerns have been raised regarding the association between long-term therapy with all-cause mortality, haemorrhagic stroke and prostate cancer. ${ }^{64}$ Currently vitamin $\mathrm{E}$ is recommended as a treatment option for selected patients with biopsy-proven NASH. There is no convincing evidence that vitamin $\mathrm{E}$ improves liver fibrosis.

Several pharmaceutical agents, including obeticholic acid (OCA), elafibranor, selonsertib and cenicriviroc, are currently in phase III of randomised controlled trials to assess their potential role in the management of NAFLD. OCA activates the farnesoid $\mathrm{X}$ nuclear receptor in the liver, leading to improved hepatic insulin sensitivity and decreased gluconeogenesis, inflammation, lipogenesis and fibrosis. ${ }^{65}$ Unfortunately, with treatment there is a rapid rise in low-density lipoprotein cholesterol, and although this side effect can be treated effectively with statin medication, the cardiovascular consequences of OCA treatment are unknown. ${ }^{66}$ Elafibranor is an agonist of PPAR $\alpha$ and PPAR $\delta$. Elafibranor improves insulin sensitivity and reduces hepatic inflammation in mouse models. ${ }^{67}$ Initial results have shown some promise in resolving moderate to severe NASH (although not mild) and improving cardiometabolic risk factors. ${ }^{68}$ Selonsertib acts to inhibit apoptosis signal-regulating kinase 1 , which is involved in hepatocyte apoptosis and fibrosis. ${ }^{69}$ During the phase II trial patients receiving selonsertib demonstrated improvements in several measures of liver disease severity, including fibrosis stage and liver fat content. ${ }^{70}$ Cenicriviroc, a C-C motif chemokine receptor- $2 / 5$ antagonist, reduces inflammation, has antifibrotic effects and improves insulin sensitivity. A phase II trial found a significant improvement in hepatic fibrosis after 1 year of treatment in $20 \%$ compared with $10 \%$ in the placebo group. ${ }^{71}$

Given the close association between T2DM and NAFLD, the effect of antidiabetic drugs in the management of NAFLD has been investigated. Although pioglitazone is the only approved antidiabetic medication for NASH, glucagon-like-peptide-1 (GLP-1) agonists, such as liraglutide, have also shown promise. These agonists have a longer half-life than endogenous GLP-1 but produce the same effects of stimulating insulin secretion, inhibiting glucagon secretion, decreasing hepatic glucose production and delaying gastric emptying. ${ }^{72}$ Additionally, GLP-1 agonists promote weight loss, which is thought to be through inducing satiety, although it may in part be through increased thermogenesis in brown adipose tissue. ${ }^{73}$ The response rate to liraglutide, in terms of resolution of NASH, is $30 \%$ above placebo. ${ }^{72}$ These agents have additional benefit on metabolic risk factors including weight, glucose levels and lipid profiles. ${ }^{72}$ Although current data are promising, the findings from larger randomised control trials are awaited. Sodium-glucose cotransporter-2 (SGLT2) inhibitors have been demonstrated in several pilot studies to significantly reduce ALT levels and body weight and the fatty liver index in patients with NAFLD. ${ }^{74}$ The impact of SGLT2 inhibitors on liver histology is not confirmed, and therefore further trials are ongoing. Other antidiabetic agents, including metformin and dipeptidyl peptidase-4 inhibitors, have no reliable data regarding beneficial effects in NAFLD.

\section{CONCLUSION}

There is a growing epidemic of NAFLD in many developed countries because of the high prevalence of obesity in ageing populations. Features of MetS or abnormal liver biochemistry should prompt healthcare professionals to consider a potential diagnosis of NAFLD. Although many investigative approaches exist, ultrasound is a simple and inexpensive first-line imaging technique to diagnose hepatic steatosis, and together with simple biochemical and immunological tests can rule out alternative pathologies. More specialist investigations, such as the ELF test and TE scans, are becoming available in primary care to diagnose liver fibrosis, and the use of these tests helps non-specialists identify those patients with NAFLD at higher risk of liver morbidity and mortality who require specialist referral and input. ${ }^{76}$ In patients with NAFLD, there is increased morbidity and mortality from T2DM and cardiovascular disease; therefore, it is important that NAFLD is considered as a common chronic liver disease with frequently occurring extrahepatic complications. As more accurate imaging techniques become widely available, the need for invasive and expensive liver biopsies will decrease. Lifestyle interventions focused around weight loss are still the mainstay for management, although new agents such as GLP-1 agonists that promote weight loss are showing promise in the treatment of NASH. Increased availability of more advanced imaging techniques and further research into novel pharmacological treatments will surely improve the investigative and management approach towards NAFLD in the very near future.

\section{Main messages}

Features of the metabolic syndrome or abnormal liver biochemistry should prompt healthcare professionals to consider a potential diagnosis of non-alcoholic fatty liver disease (NAFLD).

- Liver ultrasound is a pragmatic first-line test to diagnose hepatic steatosis in NAFLD and to exclude other liver pathology such as liver metastases or gallstones that may also cause relatively small changes in biochemical liver tests.

- In those with confirmed hepatic steatosis, use simple noninvasive markers of fibrosis, such as the Enhanced Liver Fibrosis score or Fibrosis-4 (FIB-4) score, and a test of liver stiffness such as a 'FibroScan', to investigate for liver fibrosis.

- Lifestyle interventions focused around weight loss are the mainstay for management of patients with hepatic steatosis and/or mild liver fibrosis.

- Pioglitazone and vitamin E (where not contraindicated) are currently recommended for patients with non-alcoholic steatohepatitis, but new agents such as glucagon-likepeptide-1 agonists that promote weight loss are showing promise. 
Current research questions

- How can the spectrum of liver disease (liver fat, inflammation and fibrosis) be diagnosed in non-alcoholic fatty liver disease (NAFLD)?

- What treatments are recommended for non-alcoholic steatohepatitis (NASH) and which patients with NASH require regular surveillance for complications of NAFLD?

- If patients with NASH are treated with a recommended therapy, how should treatment response be monitored over time?

\section{Key references}

1. Byrne CD, Targher G. NAFLD: a multisystem disease. J Hepatol 2015;62(1 Suppl):S47-64.

2. Targher G, Byrne CD, Lonardo A, et al. Non-alcoholic fatty liver disease and risk of incident cardiovascular disease: metaanalysis. J Hepatol 2016;65:589-600.

3. Mantovani A, Byrne CD, Bonora $E$, et al. Nonalcoholic fatty liver disease and risk of incident type 2 diabetes: a metaanalysis. Diabetes Care 2018;41:372-82.

4. Byrne CD, Patel J, Scorletti E, et al. Tests for diagnosing and monitoring non-alcoholic fatty liver disease in adults. BMJ 2018;362:k2734.

5. Bedogni G, Miglioli L, Masutti F, et al. Incidence and natural course of fatty liver in the general population: the Dionysos study. Hepatology 2007;46:1387-91

\section{Self assessment questions}

1. The majority of individuals who have type 2 diabetes mellitus have hepatic steatosis.

2. Abnormal liver biochemistry, such as raised aminotransferase levels, is a reliable early marker of non-alcoholic fatty liver disease.

3. The diagnosis of non-alcoholic fatty liver disease can be made with imaging alone.

4. Ultrasound has a good sensitivity in detecting mild hepatic steatosis.

5. The only drugs currently recommended for the treatment of non-alcoholic steatohepatitis are pioglitazone and vitamin $\mathrm{E}$.

Contributors EJ wrote the article, performed the literature search and is the guarantor. CDB was asked to write the article by the PMJ editorial team and helped to write the article. JP and ES helped in the writing and editing of the article.

Funding CDB is supported in part by the National Institute for Health Research (NIHR) Southampton Biomedical Research Centre.

Competing interests None declared.

Patient consent for publication Not required.

Provenance and peer review Commissioned; externally peer reviewed

\section{REFERENCES}

1 Bedogni G, Miglioli L, Masutti F, et al. Incidence and natural course of fatty liver in the general population: the Dionysos study. Hepatology 2007;46:1387-91.

2 NCD Risk Factor Collaboration (NCD-RisC). Trends in adult body-mass index in 200 countries from 1975 to 2014: a pooled analysis of 1698 population-based measurement studies with $19 \cdot 2$ million participants. Lancet 2016;387:1377-96.

3 Charlton MR, Burns JM, Pedersen RA, et al. Frequency and outcomes of liver transplantation for nonalcoholic steatohepatitis in the United States. Gastroenterology 2011;141:1249-53
4 Singh S, Allen AM, Wang Z, et al. Fibrosis progression in nonalcoholic fatty liver vs nonalcoholic steatohepatitis: a systematic review and meta-analysis of paired-biopsy studies. Clin Gastroenterol Hepatol 2015;13:643-54. e1-9; quiz e39-40.

5 Angulo P. Long-term mortality in nonalcoholic fatty liver disease: is liver histology of any prognostic significance? Hepatology 2010;51:373-5.

6 Targher G, Day CP, Bonora E. Risk of cardiovascular disease in patients with nonalcoholic fatty liver disease. N Engl J Med 2010;363:1341-50.

7 Targher G, Byrne CD, Lonardo A, et al. Non-alcoholic fatty liver disease and risk of incident cardiovascular disease: a meta-analysis. J Hepatol 2016;65:589-600.

8 Mantovani A, Byrne CD, Bonora $\mathrm{E}$, et al. Nonalcoholic fatty liver disease and risk of incident type 2 diabetes: a meta-analysis. Diabetes Care 2018;41:372-82.

9 Söderberg C, Stål P, Askling J, et al. Decreased survival of subjects with elevated liver function tests during a 28-year follow-up. Hepatology 2010;51:595-602.

10 Byrne CD, Targher G. NAFLD: a multisystem disease. J Hepatol 2015;62(1 Suppl):S47-64.

11 Sanai FM, Keeffe EB. Liver biopsy for histological assessment: the case against. Saudi J Gastroenterol 2010;16:124-32.

12 Browning JD, Szczepaniak LS, Dobbins R, et al. Prevalence of hepatic steatosis in an urban population in the United States: impact of ethnicity. Hepatology 2004;40:1387-95

13 Prati D, Taioli E, Zanella A, et al. Updated definitions of healthy ranges for serum alanine aminotransferase levels. Ann Intern Med 2002;137:1-10.

14 Leite NC, Salles GF, Araujo ALE, et al. Prevalence and associated factors of nonalcoholic fatty liver disease in patients with type-2 diabetes mellitus. Liver Int 2009;29:113-9.

15 Targher G, Bertolini L, Padovani R, et al. Prevalence of nonalcoholic fatty liver disease and its association with cardiovascular disease among type 2 diabetic patients. Diabetes Care 2007;30:1212-8.

16 Assy N, Kaita K, Mymin D, et al. Fatty infiltration of liver in hyperlipidemic patients. Dig Dis Sci 2000;45:1929-34.

17 Lau K, Lorbeer R, Haring R, et al. The association between fatty liver disease and blood pressure in a population-based prospective longitudinal study. $J$ Hypertens 2010;28:1829-35.

18 López-Suárez A, Guerrero JMR, Elvira-González J, et al. Nonalcoholic fatty liver disease is associated with blood pressure in hypertensive and nonhypertensive individuals from the general population with normal levels of alanine aminotransferase. Eur $J$ Gastroenterol Hepatol 2011;23:1-7.

19 Ryan MC, Wilson AM, Slavin J, et al. Associations between liver histology and severity of the metabolic syndrome in subjects with nonalcoholic fatty liver disease. Diabetes Care 2005:28:1222-4.

20 Marchesini Get al. Nonalcoholic fatty liver, steatohepatitis, and the metabolic syndrome. Hepatology 2003:37:917-23.

21 Koehler EM, Schouten JNL, Hansen BE, et al. External validation of the fatty liver index for identifying nonalcoholic fatty liver disease in a population-based study. Clin Gastroenterol Hepatol 2013;11:1201-4.

22 Kotronen A, Peltonen M, Hakkarainen A, et al. Prediction of non-alcoholic fatty liver disease and liver fat using metabolic and genetic factors. Gastroenterology 2009:137:865-72.

23 Chamoun Z, Vacca F, Parton RG, et al. PNPLA3/adiponutrin functions in lipid droplet formation. Biol Cell 2013:105:219-33.

24 Lee SS, Byoun Y-S, Jeong S-H, et al. Role of the PNPLA3 I148M polymorphism in nonalcoholic fatty liver disease and fibrosis in Korea. Dig Dis Sci 2014; 59:2967-74.

25 Romeo S, Sentinelli F, Dash S, et al. Morbid obesity exposes the association between PNPLA3 1148M (rs738409) and indices of hepatic injury in individuals of European descent. Int J Obes 2010;34:190-4. 2005

26 Romeo S, Sentinelli F, Cambuli VM, et al. The 148M allele of the PNPLA3 gene is associated with indices of liver damage early in life. J Hepatol 2010;53:335-8.

27 Romeo S, Kozlitina J, Xing C, et al. Genetic variation in PNPLA3 confers susceptibility to nonalcoholic fatty liver disease. Nat Genet 2008;40:1461-5.

28 Hernaez R, Lazo M, Bonekamp S, et al. Diagnostic accuracy and reliability of ultrasonography for the detection of fatty liver: a meta-analysis. Hepatology 2011:54:1082-90.

29 Ballestri S, Nascimbeni F, Baldelli E, et al. Ultrasonographic fatty liver indicator detects mild steatosis and correlates with metabolic/histological parameters in various liver diseases. Metabolism 2017;72:57-65

30 Saadeh S, Younossi ZM, Remer EM, et al. The utility of radiological imaging in nonalcoholic fatty liver disease. Gastroenterology 2002;123:745-50.

31 Strauss S, Gavish E, Gottlieb P, et al. Interobserver and intraobserver variability in the sonographic assessment of fatty liver. AJR Am J Roentgenol 2007;189:W320-W323.

32 Saverymuttu SH, Joseph AE, Maxwell JD. Ultrasound scanning in the detection of hepatic fibrosis and steatosis. Br Med J 1986:292:13-15.

33 de Lédinghen V, Vergniol J, Foucher J, et al. Non-invasive diagnosis of liver steatosis using controlled attenuation parameter (CAP) and transient elastography. Liver Int 2012;32:911-8.

34 Zhang B, Ding F, Chen T, et al. Ultrasound hepatic/renal ratio and hepatic attenuation rate for quantifying liver fat content. World J Gastroenterol 2014;20:17985-92. 
35 Lee SS, Park SH, Kim HJ, et al. Non-invasive assessment of hepatic steatosis: prospective comparison of the accuracy of imaging examinations. J Hepatol 2010;52:579-85.

36 Noureddin M, Lam J, Peterson MR, et al. Utility of magnetic resonance imaging versus histology for quantifying changes in liver fat in nonalcoholic fatty liver disease trials. Hepatology 2013;58:1930-40.

37 Georgoff $\mathrm{P}$, Thomasson D, Louie A, et al. Hydrogen-1 MR spectroscopy for measurement and diagnosis of hepatic steatosis. American Journal of Roentgenology 2012;199:2-7

38 Idilman IS, Aniktar H, Idilman R, et al. Hepatic steatosis: quantification by proton density fat fraction with MR imaging versus liver biopsy. Radiology 2013;267:767-75.

39 Feldstein AE, Canbay A, Angulo P, et al. Hepatocyte apoptosis and Fas expression are prominent features of human nonalcoholic steatohepatitis. Gastroenterology 2003; 125:437-43.

40 Tanwar S, Trembling PM, Guha IN, et al. Validation of terminal peptide of procollagen III for the detection and assessment of nonalcoholic steatohepatitis in patients with nonalcoholic fatty liver disease. Hepatology 2013;57:103-11.

41 Pavlides M, Banerjee R, Tunnicliffe EM, et al. Multiparametric magnetic resonance imaging for the assessment of non-alcoholic fatty liver disease severity. Liver International 2017;37:1065-73.

42 Nice guideline. Cirrhosis in over 16S: assessment and management, 2016. Available: https://www.nice.org.uk/guidance/ng50/chapter/Recommendations\#monitoring [Accessed 17 Jan 2019].

43 Harrison SA, Oliver D, Arnold HL, et al. Development and validation of a simple NAFLD clinical scoring system for identifying patients without advanced disease. Gut 2008:57:1441-7.

44 Shah AG, Lydecker A, Murray K, et al. Comparison of noninvasive markers of fibrosis in patients with nonalcoholic fatty liver disease. Clinical Gastroenterology and Hepatology 2009;7:1104-12.

45 Guha IN, Parkes J, Roderick P, et al. Noninvasive markers of fibrosis in nonalcoholic fatty liver disease: validating the European liver fibrosis panel and exploring simple markers. Hepatology 2008;47:455-60.

46 Glen J, Floros L, Day C, et al. Non-alcoholic fatty liver disease (NAFLD): summary of NICE guidance. BMJ 2016;354.

47 Talwalkar JA, Kurtz DM, Schoenleber SJ, et al. Ultrasound-based transient elastography for the detection of hepatic fibrosis: systematic review and metaanalysis. Clinical Gastroenterology and Hepatology 2007;5:1214-20.

48 Castéra L, Foucher J, Bernard P-H, et al. Pitfalls of liver stiffness measurement: a 5-year prospective study of 13,369 examinations. Hepatology 2010;29:828-35.

49 Yoshioka K, Hashimoto S, Kawabe N. Measurement of liver stiffness as a noninvasive method for diagnosis of non-alcoholic fatty liver disease. Hepatol Res 2015:45:142-51.

50 Liu H, Fu J, Hong R, et al. Acoustic Radiation Force Impulse Elastography for the NonInvasive Evaluation of Hepatic Fibrosis in Non-Alcoholic Fatty Liver Disease Patients: A Systematic Review \& Meta-Analysis. PLoS One 2015;10:e0127782.

51 Loomba R, Wolfson T, Ang B, et al. Magnetic resonance elastography predicts advanced fibrosis in patients with nonalcoholic fatty liver disease: a prospective study. Hepatology 2014;60:1920-8.

52 Banerjee R, Pavlides M, Tunnicliffe EM, et al. Multiparametric magnetic resonance for the non-invasive diagnosis of liver disease. J Hepatol 2014;60:69-77.

53 Promrat K, Kleiner DE, Niemeier HM, et al. Randomized controlled trial testing the effects of weight loss on nonalcoholic steatohepatitis. Hepatology 2010:51:121-9.

54 Boden G. High- or low-carbohydrate diets: which is better for weight loss, insulin resistance, and fatty livers? Gastroenterology 2009;136:1490-2.

55 Ratziu V, Goodman Z, Sanyal A. Current efforts and trends in the treatment of NASH. J Hepatol 2015;62(1 Suppl):S65-S75.

56 Moschen AR, Molnar C, Geiger S, et al. Anti-inflammatory effects of excessive weight loss: potent suppression of adipose interleukin 6 and tumour necrosis factor expression. Gut 2010;59:1259-64.

57 Ryan MC, Itsiopoulos C, Thodis T, et al. The Mediterranean diet improves hepatic steatosis and insulin sensitivity in individuals with non-alcoholic fatty liver disease. J Hepatol 2013;59:138-43.

58 JG Y, Javorschi S, Hevener AL, et al. The effect of thiazolidinediones on plasma adiponectin levels in normal, obese, and type 2 diabetic subjects. Diabetes 2002;51:2968-74

59 Cusi K, Orsak B, Bril F, et al. Long-term pioglitazone treatment for patients with nonalcoholic steatohepatitis and prediabetes or type 2 diabetes mellitus. Ann Intern Med 2016;165:305-15.

60 Sanyal AJ, Chalasani N, Kowdley KV, et al. Pioglitazone, vitamin E, or placebo for nonalcoholic steatohepatitis. N Engl J Med 2010;362:1675-85.

61 Ratziu V, Charlotte F, Bernhardt C, et al. Long-term efficacy of rosiglitazone in nonalcoholic steatohepatitis: results of the fatty liver improvement by rosiglitazone therapy (FLIRT 2) extension trial. Hepatology 2010;51:445-53.
62 Ekstedt M, Hagström H, Nasr P, et al. Fibrosis stage is the strongest predictor for disease-specific mortality in NAFLD after up to 33 years of follow-up. Hepatology 2015;61:1547-54.

63 El Hadi HVR, Rossato M. Handbook of famine, starvation, and nutrient deprivation. Switzerland: Springer International Publishing, 2018: 1-18.

64 Dyson JK, Anstee QM, McPherson S. Republished: non-alcoholic fatty liver disease: a practical approach to treatment. Postgrad Med J 2015;91:92-101.

65 Rinella ME, Sanyal AJ. NAFLD in 2014: genetics, diagnostics and therapeutic advances in NAFLD. Nat Rev Gastroenterol Hepatol 2015;12:65-6.

66 Neuschwander-Tetri BA, Loomba R, Sanyal AJ, et al. Farnesoid X nuclear receptor ligand obeticholic acid for non-cirrhotic, non-alcoholic steatohepatitis (Flint): a multicentre, randomised, placebo-controlled trial. Lancet 2015;385:956-65.

67 Staels B, Rubenstrunk A, Noel B, et al. Hepatoprotective effects of the dual peroxisome proliferator-activated receptor alpha/delta agonist, GFT505, in rodent models of nonalcoholic fatty liver disease/nonalcoholic steatohepatitis. Hepatology 2013;58:1941-52.

68 Ratziu V, Harrison SA, Francque S, et al. Elafibranor, an Agonist of the Peroxisome Proliferator-Activated Receptor $-\alpha$ and $-\delta$, Induces Resolution of Nonalcoholic Steatohepatitis Without Fibrosis Worsening. Gastroenterology 2016;150:1147-59.

69 Brenner C, Galluzzi L, Kepp 0, et al. Decoding cell death signals in liver inflammation. J Hepatol 2013;59:583-94.

70 Loomba R, Lawitz E, Mantry PS, et al. The ASK1 inhibitor selonsertib in patients with nonalcoholic steatohepatitis: a randomized, phase 2 trial. Hepatology 2018;67:549-59

71 Friedman SL, Ratziu V, Harrison SA, et al. A randomized, placebo-controlled trial of cenicriviroc for treatment of nonalcoholic steatohepatitis with fibrosis. Hepatology 2018;67:1754-67.

72 Armstrong MJ, Gaunt P, Aithal GP, et al. Liraglutide safety and efficacy in patients with non-alcoholic steatohepatitis (lean): a multicentre, double-blind, randomised, placebocontrolled phase 2 study. Lancet 2016:387:679-90.

73 Drucker DJ. Deciphering metabolic messages from the gut drives Therapeutic Innovation: the 2014 Banting lecture. Diabetes 2015;64:317-26.

74 Seko Y, Sumida Y, Tanaka S, et al. Effect of sodium glucose cotransporter 2 inhibitor on liver function tests in Japanese patients with non-alcoholic fatty liver disease and type 2 diabetes mellitus. Hepatol Res 2017;47:1072-8.

75 Takase T, Nakamura A, Miyoshi $\mathrm{H}$, et al. Amelioration of fatty liver index in patients with type 2 diabetes on ipragliflozin: an association with glucose-lowering effects. Endocr J 2017;64:363-7.

76 Byrne CD, Patel J, Scorletti E, et al. Tests for diagnosing and monitoring non-alcoholic fatty liver disease in adults. BMJ 2018:362.

77 Schwenzer NF, Springer F, Schraml C, et al. Non-invasive assessment and quantification of liver steatosis by ultrasound, computed tomography and magnetic resonance. J Hepatol 2009;51:433-45.

78 Dulai PS, Sirlin CB, Loomba R. MRI and MRE for non-invasive quantitative assessment of hepatic steatosis and fibrosis in NAFLD and NASH: clinical trials to clinical practice. J Hepatol 2016;65:1006-16

79 Angulo P, Hui JM, Marchesini G, et al. The NAFLD fibrosis score: a noninvasive system that identifies liver fibrosis in patients with NAFLD. Hepatology 2007;45:846-54.

80 McPherson S, Hardy T, Dufour J-F, et al. Age as a confounding factor for the accurate non-invasive diagnosis of advanced NAFLD fibrosis. Am J Gastroenterol 2017:112:740-51.

81 Tapper EB, Challies T, Nasser I, et al. The performance of vibration controlled transient elastography in a US cohort of patients with nonalcoholic fatty liver disease. Am Gastroenterol 2016;111:677-84.

82 Friedrich-Rust M, Ong M-F, Martens S, et al. Performance of transient elastography for the staging of liver fibrosis: a meta-analysis. Gastroenterology 2008;134:960-74.

83 Kiani A, Brun V, Lainé $F$, et al. Acoustic radiation force impulse imaging for assessing liver fibrosis in alcoholic liver disease. World J Gastroenterol 2016:22:4926-35.

Answers

1. True.

2. False.

3. False.

4. False.

5. True. 